\title{
CORPOS MOdIFICADOS/ALTERADOS. ENTRE A MODA E OS PROJETOS DE IDENTIDADE
}

\author{
Ambrogia Cereda \\ ambrogia.cereda@unicatt.it \\ Università Cattolica del Sacro Cuore, Milan
}

\begin{abstract}
Resumo
O corpo tem vindo a desempenhar de forma crescente um papel crucial no contexto social, onde a aparência representa a esfera privilegiada para a auto-expressão e para a construção da identidade. Entre as muitas maneiras de decorar, adornar e camuflar o corpo, algumas técnicas tradicionais (as tatuagens, o piercing, a escarificação) competem com técnicas mais recentes e tecnológicas (a cirurgia estética, implantes) para modelar e retratar individualidades. Por um lado, essas técnicas estão a utilizar propósitos e códigos de apresentação do mundo da moda. Por outro lado, desafiam esssa fluidez e mudança contínua ao materializarem projetos de identidade a longo prazo cujo objetivo é resistir à transformação. Em ambos os casos, os indivíduos referem-se ao corpo como um domínio privilegiado para narrar e refletir sobre a sua própria história pessoal, parecendo também sentir-se mais capazes de gerir as diferentes técnicas e de as misturar para atingir os seus próprios propósitos expressivos. O resultado é uma combinação de códigos visuais que consegue revelar diferentes modelos corporais, bem como diferentes formas de experienciar a corporalidade e a personificação. Este artigo procura dar conta desta variedade, com referência a uma pesquisa desenvolvida sobre quatro técnicas (a tatuagem, a escarificação, a cirurgia estética e o piercing) entre um gupo de utilizadores e profissionais.
\end{abstract}

\section{Palavras-chave}

Projeto do corpo, Identidade, Tatuagem, Piercing, Personificação

\section{INTRODUÇÃo}

As teorias contemporâneas sobre o papel do corpo na sociedade apontam para a importância crescente da aparência como um domínio privilegiado para a construção e expressão da nossa identidade individual. Neste enquadramento, modificar o corpo e trabalhar sobre a sua superfície utilizando diferentes técnicas (vestuário, maquilhagem, tatuagem, cirurgia) representam os pré-requisitos necessários para participar nas interações sociais quotidianas: um visual bem conseguido funciona como um visto para uma integração bem sucedida no grupo social.

A moda - considerada como um meio de expressão da identidade - participa neste processo como uma das fontes mais influentes para a recriação do eu individual:

Crescemos a acreditar que a moda (e gerações de escritores na míriade de revistas têm contribuído para esta convicção) é uma deusa misteriosa, a cujos decretos é nosso dever obedecer mais do que compreender porque, na verdade, está implícito que estes decretos transcendem toda a comum compreensão humana. Não sabemos porque são feitos, ou por quanto tempo irão perdurar, mas apenas que devem ser seguidos, e que quanto 
mais rápida for a obediência, maior será o mérito (Fluegel, 1930: 137, citado em Kawamura, 2004: 44).

A forma do corpo e a aparência são materializadas seguindo as regras do sistema simbólico intangível por meio do vestuário e de outras técnicas de adorno pessoal que constituem um conjunto de ferramentas disponível. Neste enquadramento, os meios de comunicação social e a publicidade fornecem materiais visuais para a transformação total: numa revista qualquer um pode encontrar uma ampla variedade de sugestões sobre formas visuais e formas corporais de sucesso para qualquer estação. Isto torna-se particularmente evidente no contexto italiano, onde a moda tem representado um meio tradicional de integração social desde a Idade Média e ainda é considerada como provedora de modelos de aceitação, mais do que como forma de expressões anti- culturais (Mora, 2009). Neste contexto, a manutenção do corpo e a modificação corporal parecem entrar no sistema da moda como estratégias chave para a personificação.

Tentarei trazer alguma clareza sobre estas práticas para articular a sua função como ferramentas para a identidade; ao debruçar-me sobre quatro diferentes técnicas (tatuagem, piercing, escarificação, cirurgia estética) e fornecendo dados colhidos numa' pesquisa empírica, o papel do corpo será questionado e as tipologias do corpo serão delineadas como realizações de identidades situadas, reflexivas e representadas.

\section{MuITOS EUS, QUE CORPO?}

Vivemos num mundo social ambivalente, no qual tensões sobre os papéis de género, estatuto social e a expressão da sexualidade podem ser encontradas em qualquer arena social, dos meios de comunicação social ao trabalho, da política à educação. Tentar prever qual será o aspeto das pessoas parece um jogo arriscado, escondendo uma relação extremamente incerta entre o eu privado e a identidade pública. No entanto, o corpo nunca esteve tão presente e nunca foi tão crucial nas representações da cultura de consumo e da moda, como tem ocorrido nas últimas décadas, e é sugerido como propriedade pessoal que todos podem moldar consoante lhes aprouver. $\mathrm{Na}$ verdade, a nossa corporalidade tem-se tornado o equivalente a um objecto que pode ser manipulado, exibido e atualizado, tornando o poder social invisível de forma crescente (Turner, 1985). É este o mesmo corpo através do qual temos experiências e perceções na nossa vida quotidiana e que não nos pertence apenas a nós, mas é nós próprios (Merleau-Ponty, 1954)?

Os estudos de moda tendem a considerar a corporalidade como um não-fenómeno, algo que necessita de ser culturalizado, uma vez que sem a ajuda do vestuário seria uma mera materialidade que é quase ininteligível (Entwistle, 2000). Mas após ter sido domado através de elementos de cultura muito precisos (roupas, ornamentos, tatuagens, piercing, maquilhagem, perfume), os corpos podem entrar no domínio da significação.

\footnotetext{
' A pesquisa foi realizada adotando uma metodologia qualitativa (1 mês de observação participante em estúdios de tatuagem e 20 entrevistas aprofundadas a tatuadores profissionais, piercers, cirurgiões e utilizadores comuns das práticas corporais selecionadas), os corpos modificados são investigados como um patamar entre a passagem individual para a diferenciação e a necessidade comum de pertença a uma comunidade.
} 
Roland Barthes (1993) retratou este domínio como um espectáculo, onde o corpo humano está adaptado a um modelo - geralmente fornecido pela moda — acessível a quem decidir transmitir o papel complexo que se quer desempenhar. Por conseguinte, enquanto nos fornece peças de vestuário que transmitem o que queremos comunicar sobre nós, o sistema da moda torna-nos não apenas inteligíveis, como também classificáveis. Nesta perspectiva, para além da sua capacidade de comunicar ideias, emoções ou de realizar operações simbólicas e técnicas complicadas (por exemplo, dançar, cantar, atuar, operações cirúrgicas), o nosso corpo torna-se o suporte para um intercâmbio social mais frutífero e é rapidamente transformado na expressão do gosto pessoal e das ideias. Uma nova variabilidade no panorama da moda não só envolve o corpo social, mas também o corpo físico, que é cada vez mais separado da biologia, modificado e moldado graças a muitos aparelhos diferentes: o fitness, a dieta, o uso de próteses, a cultura do corpo/ body-building, a cirurgia estética, o fetichismo, a tatuagem e os produtos de cosmética, são as novas ferramentas para a comunicação. Os corpos são, assim, concebidos como uma mutação contínua e qualquer um se pode tornar um body-flux (Codeluppi, 1992: 85), que perdeu qualquer fronteira e identidade precisas, pode ser confundido com o seu contexto exterior e ter intercâmbios ininterruptos de fluxo para o exterior.

Os efeitos deste processo são epitomizados pelo comportamento dos jovens na moda e na sua preocupação com a aparência. A sua presença mais significativa no mundo da moda, em todos os níveis sociais, já foi ilustrada como um elemento fundamental na agenda social (Crane, 2000). Além disso, eles parecem ter-se transformado nos "escolhidos" no domínio do consumo, devido à sua capacidade em mediar as suas relações com diferentes cenários (Mora, 2009). Os jovens estão, de facto, mais interessados em descodificar as mensagens incorporadas nos produtos da cultura de massas e que se encontram disponíveis no mercado. Mesmo que a sua atitude pareça menos flexível do que o seu corpo, na medida em que seguem as sugestões de revistas e dos novos meios de comunicação e julgam de uma forma negativa as performances corporais de quem não está em sintonia com os seus estereótipos de idade, profissão e género (Pietropolli Charmet e Marcazzan, 2000; Stagi, 2008). Eles parecem ter decorado a lição sobre como devem utilizar os seus corpos e aplicar os procedimentos da tatuagem, do piercing e da cirurgia estética, como sendo partes integrantes do seu código de moda, ferramentas utilizadas para a socialização e reconhecimento social.

Pesquisas recentes assinalaram o hiato profundo que separa as práticas quotidianas de como vestir-se dos modelos ideais transmitidos pelos meios de comunicação. Ilustram como as representações sugeridas pelas campanhas de marcas de moda famosas se baseiam em poucos modelos femininos e são frequentemente extremos, uma vez que basicamente promovem um tipo de mulher objetificada e subordinada (Ruggerone 2006; Diaz Soloaga e Muñiz Muriel, 2008). No entanto, a atitude tomada para ligar a identidade individual e as representações mediadas que estão na moda não é apenas uma "prática da juventude", mas cada vez mais envolve adultos em diferentes idades e posições sociais, devido à influência exercida pelas representações das identidades de género transmitidas pelas revistas glamorosas da moda e pelos jornais e ocupando uma parte importante da agenda cultural (Wykes e Gunter, 2005). 
Na realidade, supostamente poucos de nós estarão directamente empenhados em cumprir os ditames dos designers da moda, enquanto a maioria das pessoas tenta encontrar um rumo no conjunto super-saturado de imagens transmitidas pelos anúncios da moda. Numa dimensão mais privada, os jovens parecem ter desenvolvido hábitos psicológicos que os tornam cada vez mais capazes de introspecção e, consequentemente, particularmente vulneráveis à excessiva e negativa preocupação com as suas próprias perceções do corpo e com as perceções dos outros (Simmons, Blyth e McKinney, 1983). Esta mesma preocupação, no entanto, parece ser um assunto tipicamente Ocidental e está relacionada com as performances corporais em actividades quotidianas que transformaram a modificação voluntária da nossa aparência corporal numa acção óbvia (Le Breton, 2002).

A utilização crescente da tatuagem, do piercing e de outras práticas mais invasivas ou dolorosas (por exemplo, a cirurgia estética e a escarificação) não só se impinge a uma mentalidade "naturalista" mais antiga, mas também ao risco de perder o controlo sobre a nossa vida. Assim sendo, a modificação do nosso corpo representa "um gesto contra o corpo natural e a tirania da formação de habitus" (Featherstone, 2000: 2). A prática de modificação do corpo, na verdade, proporciona uma sensação de estar em controlo que representa por si só um valor e uma opção que pode ser seleccionada de maneira a reduzir os riscos e a ansiedade devido a uma crescente instabilidade do cenário social, composto por uma variedade de possibilidades de personificação. Os dados da pesquisa assinalaram a importância de exibir a "aparência certa" nas interações sociais entre os jovens estudantes, como a difusão de um fenómeno designado por body tuning no qual os corpos individuais são adaptados aos requisitos da situação, dando lugar a múltiplas e súbitas identificações e a transformações instantâneas da nossa aparência física (Stagi, 2008). Trabalhar sobre a superfície corporal em diferentes níveis (através do vestuário, mas também através do piercing, tatuagem ou cirurgia estética) torna-se um meio privilegiado de produção de uma identidade bem sucedida em qualquer situação.

Este modelo foi promovido nos finais dos anos 80 , com a crescente cultura de consumo que enfatizava a aparência como uma característica fulcral da vida social e interligava os preceitos médicos da manutenção do corpo e as sugestões hedonistas de fruição corporal:

A cultura de consumo encaixa com a conceção predominante auto-preservacionista do corpo, que encoraja o indivíduo a adotar estratégias instrumentais para combater a deterioração e a decadência (aplaudidas também pelas burocracias do Estado, que procuram reduzir os custos de saúde, educando o público e combatendo a negligência do corpo) e combina-a com a noção de que o corpo é um veículo de prazer e de auto-expressão. As imagens de um corpo belo, abertamente sexual e associado ao hedonismo, ao lazer e à exposição pública, enfatizam a importância da aparência e do "visual" (Featherstone, 1991: 170). 
Hoje em dia esta convicção é partilhada por qualquer indivíduo que é sensível a expectativas sociais e que aprendeu que a imagem corporal é entendida como uma tarefa a ser conseguida através do uso da tecnologia, da biologia, da cultura e de qualquer aparelho disponível no contexto social (Shilling, 2003). Esta tarefa adquire as características de um projecto para o indivíduo (Giddens, 1991) que apaga as diferenças entre aquilo que é natural e o que foi naturalizado e selecciona os seus/as suas próprias práticas corporais para "concluir" o trabalho através de escolhas de estilos de vida.

A ideia do corpo como projecto não implica que todos tenham a predisposição ou a capacidade para transformarem radicalmente o seu corpo. Pressupõe, sim, que as pessoas normalmente estão conscientes destes desenvolvimentos transformadores e que existe uma forte tendência nas sociedades ocidentais contemporâneas para se associarem aos seus corpos e se preocuparem cada vez mais com eles. (Shilling, 2003: 174)

Mas quais são os meios para a nossa transformação? Neste ensaio analisarei, em primeiro lugar, o papel das modificações do corpo como parte de um idioma corporal partilhado (que está em moda) e como um ponto de referência na interacção social; seguidamente, refletirei sobre as representações que fornecem este tipo de conhecimento para as actividades situadas. Após delinear as tipologias dos modelos do corpo, resultantes da pesquisa empírica, discutirei a possibilidade da existência de outros tipos de corpo e de performances da identidade.

\section{MODIFICAÇÕES DO CORPO COMO PRÁTICAS MODERNAS}

Pertencemos a um sistema de conduta institucionalizado, no qual existe um conhecimento comum sobre a nossa aparência e que nós usamos para evocar nos outros aquilo que entendemos como parte da nossa expressão. Isto pode ser designado por "idioma corporal" e regula as formas através das quais qualquer pessoa deve prestar atenção às aparências (Goffman, 1963). Para as nossas performances sociais, podemos contar com uma série de técnicas que devemos observar, utilizar e para mostrar o nosso corpo em sociedade. Estas "técnicas corporais" (Mauss, 1950) que nos permitem partilhar o idioma do corpo são aprendidas desde muito cedo e implicam uma dupla experiência de personificação e de remodelação nos passos subsequentes da nossa socialização. As técnicas corporais não só fazem parte de um conjunto mais amplo de informação útil para a vida social e para transmitir coesão social, mas também representam um aperfeiçoamento deste conhecimento quando as usamos para recriar aquilo que sabemos sobre o nosso corpo e a forma como a sociedade o aceita (Leveratto, 2006).

Os meios de comunicação dominantes estruturam e representam a cirurgia cosmética, a tatuagem e o piercing corporal como métodos de modificação do corpo. As provas resultantes da análise de artigos de jornais sobre a cirurgia cosmética e a tatuagem mostram que estes são representados de forma positiva, como opções de estilos de vida do consumidor, enquanto o piercing é frequentemente enquadrado de forma negativa, como uma prática pouco saudável e problemática. De forma semelhante, os dados obtidos indicam que os riscos associados à cirurgia estética e à tatuagem são 
frequentemente subestimados, tal como a tatuagem é associada ao desvio da normalidade. Ao contrário, os potenciais riscos relacionados com o piercing corporal são sobrevalorizados (Adams, 2009).

Estas técnicas de enquadramento reflectem um entendimento social enraizado das práticas de modificação do corpo e simultaneamente informam e moldam o nosso conhecimento comum sobre as performances corporais / de identidade.

Seguindo estas interpretações, a tatuagem, a escarificação, o piercing e a cirurgia estética fazem parte do conhecimento sobre a forma como os corpos podem ser usados nas sociedades ocidentais e o que deveria ser evitado nos contextos sociais. Esta divisão é marcada através de normas sociais específicas sobre a apresentação corporal e tem sido normalizada através de uma atenção crescente para a utilização de ferramentas apropriadas para a manutenção do corpo, abandonando restrições e rigidez: deteta-sa uma tendência global para descartar as limitações puritanas sobre a indiferença, a modéstia e o distanciamento lento em relação aos outros corpos (Ory, 2009). Como resultado de uma democratização na área do cuidado com o corpo e com a estetização da aparência corporal - amplificada e apoiada pelo crescimento da indústria da maquiIhagem — os mais recentes parâmetros para a definição do nosso corpo são delineados utilizando as técnicas corporais "mais em moda" que se encontram disponíveis na nossa cultura. Estas regras têm sido redefinidas ao longo de algumas gerações e têm exigido das pessoas uma interpretação dos seus corpos como uma superfície flexível:

"O nosso corpo pode ser entendido como uma tela, na qual cada um pode fazer o seu melhor quadro". (T8)

"Penso que deveríamos interpretar o nosso corpo como o nosso lar, embelezamo-lo, decoramo-lo, é a única coisa que temos na nossa vida, portanto é nosso direito decidir como ele deveria ser apresentado." ( $\left.S_{3}\right)$

Se, por um lado, as pessoas comuns parecem procurar mudanças constantes, por outro lado, os profissionais trabalham sobre o papel do corpo como um material vivo e como uma perspetiva em qualquer situação incerta. A oportunidade de transformamos o nosso eu e a nossa aparência corporal é construída como uma liberdade limitada ou relativa. Apesar de inacabada, no corpo nós encontramos limites precisos para a materialização do que é percebido como "o nosso eu", e o problema para todos torna-se a materialização da fronteira entre a materialidade do corpo e a imaterialidade dos significados culturais.

"Estamos de volta ao discurso prévio sobre a moda. As imagens transmitidas pelos meios de comunicação, pela televisão, etc., promovem modelos que nos compelem a trazer as pessoas de volta à Terra. Não podemos pensar que nos mudamos a nós próprios como mudamos de camisa de manhã, da azul para a branca. O tecido do corpo não é como o pano, o algodão ou o linho, que pode cortado e cosido! Está vivo!!” $\left(\mathrm{CH}_{1}\right)^{2}$

\footnotetext{
${ }^{2}\left(\mathrm{CH}_{1}\right)$ refere-se à cirurgia, primeira entrevista. Neste caso particular, o entrevistado é um cirurgião italiano de 50 anos.
} 
Dando uma forma particular aos seus corpos e tornando-os mais sedutores através da cirurgia estética ou de formas mais tribais através da escarificação, os atores sociais materializam o princípio fundamental das teorias clássicas sobre a moda: querem mostrar a sua adesão a um grupo preciso, ao mesmo tempo que se distanciam uns dos outros (Simmel, 1904).

Nas práticas de modificação dos seus corpos, os atores sociais sugerem aquilo que sabem sobre o código cultural para a auto-apresentação e quais as técnicas permitidas pelo seu grupo: do nosso vestido até à cor da nossa pele, do tom da voz até ao tamanho do nosso decote, sempre mostramos que sabemos muitas coisas sobre as maneiras como um corpo se deve apresentar. Se este facto parece óbvio, não significa que a razão seja evidente, parece antes sustentar uma convenção micro-sociológica de acordo com a qual toda uma série de noções deve ser desempenhada com competência por forma a ser percebida como natural (Garfinkel, 1976).

Modificar o corpo envolve, de facto, um complexo de actividades socialmente norteadas, perceptuais, interactivas e micro-políticas que moldam determinadas atividades como expressões dos "eus". Quando vemos a expressão do eu como uma conquista, um feito, consideramos a identidade como uma propriedade alcançada da conduta concreta de um indivíduo. Em vez de ser uma propriedade de indivíduos, o eu é concebido como uma característica emergente de situações sociais: quer como um resultado, quer como uma base lógica para uma variedade de disposições sociais sobre a aparência do nosso corpo (isto é, o projecto do corpo).

A astúcia do projecto do corpo é tomada como um dado adquirido e reforçada pelo facto de parecer ser um traço natural e interno da nossa realidade. Se conseguirmos reconhecer pelo menos duas categorias de corpos - os que estão na moda e os que não estão - são muitas as formas através das quais eles foram materializados e eles representam aplicações inteligentes de regras precisas de manutenção física e de aptidões estratégicas que os indivíduos devem conhecer e utilizar como membros competentes do seu grupo (Garfinkel, 1967).

Estas técnicas não estão isentas da diferenciação de género e os efeitos sobre os corpos têm como objectivo performances com forte conotação de género. A cirurgia estética, por exemplo, é a mais conotada do ponto de vista do género, sendo utilizada por uma maioria de pacientes femininas e tendo como propósito a modificação do corpo acentuando as características sexuais a partir de um ponto de vista tipicamente masculino e heterossexual (Davis, 2002): ao recorrerem a ela, as mulheres reforçam o enfoque na aparência como uma tarefa feminina e sugerem um modelo cultural feminino específico (isto é, colocando um peito maior, lábio mais volumosos e um nariz minúsculo). Esta mesma insistência é comunicada a outras técnicas (por exemplo, a tatuagem, o piercing) que são utilizadas para dar forma a um modelo sedutor feminino de auto-apresentação, em sintonia com as representações de género dominantes.

Uma vez que é através da utilização de técnicas do corpo que o conhecimento acerca do uso social do corpo é aperfeiçoado, então é através destas mesmas técnicas que a utilização social do corpo moderno é naturalizado de acordo com um código partilhado. 
Isto implica que os atores sociais contemporâneos exibem através dos seus corpos a sua vontade em participar na chamada "cultura das aparências", subscrevendo as distinções entre os homens e as mulheres bem sucedidos/as e que cuidam da sua pele, do seu peso e do seu "visual", por oposição aos outros que negligenciam e, subsequentemente, se marginalizam a si próprios (Vigarello, 2003; Robin 2005).

Por um lado, o trabalho sobre o corpo é sugerido como uma escolha livre; por outro lado, tem de ser realizado seleccionando os materiais simbólicos corretos e a prática mais adequada para atingir o melhor resultado.

Como é que então os atores sociais têm sucesso na sua selecção de imagens corporais bem sucedidas e modernas?

\section{MODELANDO O CORPO: ENTRE OS DITAMES DA MODA E O ESTILO PESSOAL}

A moda feminina pode ser interpretada como um campo importante para fornecer representações do corpo feminino, o que se torna num texto significativo de como a cultura constrói a feminilidade e a forma como transmite essa representação às mulheres (Evans e Thornton, 1991). Em particular, os elementos sexuais eróticos da moda (Steele 1985) e a participação nas práticas da moda por aqueles que pertencem aos estratos sociais mais baixos e periféricos têm contribuído para a construção de uma representação maioritariamente feminina da moda e da preocupação coma aparência. A relação entre a beleza, a aparência física e a identidade tem sido uma questão não apenas pertencente ao pensamento feminista, que tem insistido sobre as performances relacionadas com o nosso vestuário pessoal e a reprodução estrutural de desigualdades para algumas categorias (Davis 1995; Wolf 1997), mas também tem fomentado uma reflexão mais ampla sobre o papel das imagens de modelos corporais precisos que têm atraído a atenção dos académicos e problematizado o papel dos meios de comunicação e das práticas de embelezamento (Goffman, 1979; Vigarello, 2003).

Mesmo estando enraizado no mundo feminino, o trabalho realizado na aparência individual está crescentemente a transformar-se numa tarefa universalizada, a ser conseguida utilizando os recursos disponíveis no mercado e acessível de acordo com os recursos de cada um.

Esta segunda questão relacionada com a construção moderna do corpo tem sido desenvolvida após alguma transformação recente na indústria da moda e da beleza que promovem modelos para um público masculino que aprende como pode ser criado, ou conseguido um estilo pessoal, e que mostram que um "eu elegante" é constituído por diferentes soluções oferecidas por revistas sobre estilos de vida. Cada selecção é eficaz na medida em que é descrita como tendo sido já experimentada e aprovada e, consequentemente, um homem apenas tem de procurar nas páginas, encontrar as peças de vestuário próprias e a atitude psicológica para qualquer situação (Materassi, 2010). Encontrar e colocar em prática as soluções sugeridas parece ser a resposta para uma necessidade espontânea, mas uma ambiguidade pode ser facilmente assinada. Por um lado, os estudos sobre a publicidade de moda (Bordo, 1993; Crane 2000; David et al. 2002) salientaram o papel das imagens na criação de representações de modelos corporais e de papéis de 
género, através dos quais qualquer um pode encontrar uma solução útil para o problema de nos conseguirmos comunicar a nós próprios. Por outro lado, uma vez que a moda está cada vez menos dependente da imitação entre classes sociais e cada vez mais relacionada com a necessidade de auto-expressão do indivíduo (Crane, 2000; Volonté, 2003; Bovone, 2007; Mora, 2009), a sua força como uma fonte de representações coletivas parece estar regulada pela capacidade de o indivíduo deixar a sua própria identidade aparecer através de gestos, palavras, vestuário. Em ambos os casos, tal relação depende do facto de ninguém poder ser um excluído do sistema da moda e as pessoas têm, de alguma forma, de prestar atenção ao modo como construem e interpretam as suas aparências, uma vez que não têm outro meio para se representarem (Wilson, 1985).

O poder de conseguir comunicar algo sobre o sujeito é uma característica de qualquer prática de consumo, através da qual qualquer um aprende a necessidade e o dever de transmitir a sua identidade, utilizando objectos como apoios e indicadores do seu posicionamento na sociedade (Douglas e Isherwood 1979). A tatuagem, o piercing, a escarificação e a cirurgia estética são sugeridos nos meios de comunicação (antigos e recentes) como acessórios do corpo e especialmente nas campanhas publicitárias da moda são ilustrados como fazendo parte da panóplia corporal pós-moderna. Os modelos contidos nas imagens detêm a tarefa de regular os termos dos nossos contactos com outras pessoas, as nossas emoções e intenções (Goffman, 1979). Além disso, como não têm necessidade de reflectir os factos, eles mostram as formas através das quais nós pensamos que os homens e as mulheres deveriam comportar-se e aceitamo-los como tal. No entanto, muito daquilo que nós assumimos ser a preferência individual é influenciada pelas forças sociais e culturais mais profundas (Bourdieu, 1963; Davis 1995), e pelo facto de se ter cuidado com as aparências, reconhece-se que a corporalidade é sempre o lugar para a auto-verdade contingente, resultado dos procedimentos utilizados para transformar o corpo e para o tornar visível. Nesta perspectiva, o corpo tem de ser questionado sobre o processo de expressão do eu, por forma a revelar a interligação entre as competências sobre a aparência física, a actividade situada e a identidade como uma propriedade alcançada.

\section{QUESTIONANDO O CORPO. UMA SENSIBILIDADE ETNO-METODOLÓGICA}

De que forma deve o corpo ser interrogado? A metodologia deste inquérito tem sido medida na interpretação da relação entre transformação do corpo e recriação do eu. Foram escolhidas quatro tipologias diferentes, de maneira a produzir uma representação útil de um continuum no universo das modificações do corpo, desde as mais artísticas e modernas - e consequentemente aceites - práticas (isto é, a tatuagem e a cirurgia estética) e as mais sub-culturais e pertencentes a nichos (o piercing e a escarificação). Assim, para ilustrar os eventos da personificação através da modificação do corpo, uma metodologia qualitativa surgiu como o mais útil instrumento para deixar os elementos situacionais tomados como dados adquiridos emergirem e o conhecimento 
escondido sobre actividades físicas orientadas ser revelado. Adotar a observação participativa e entrevistas aprofundadas ${ }^{3}$ tem implicado também uma perspectiva tipicamente etno-metodologista de acordo com a qual a identidade - e assim, a expressão do nosso eu - tem sido lida num sentido performativo. Nesta perspectiva, o facto de nos concentrarmos sobre os métodos utilizados pelos membros do grupo social de "modificadores do corpo" para dar um sentido às suas actividades, tem ajudado a evitar a divergência entre as práticas e as teorizações do processo de personificação.

No campo dos estudos de género tem sido prestada particular atenção à questão da metodologia, que tem revelado quase a mesma importância do objecto de pesquisa4. Neste cenário teórico, pode ser encontrada uma tendência que privilegia uma abordagem psicoanalítica e que a considera fulcral na personificação do género em particular (Irigaray, 1978; Butler, 1990; 2003). Como consequência disto, a corporalidade é interpretada como uma estrutura textual, divergindo das questões relacionadas com a materialidade vivida do corpo. Esta última é de facto analisada nas práticas dessa distância peculiar produzida entre corpos e textos em atividades concretas e em contextos sociais significativos (Howson, 2005). Observar as modificações corporais como partes de um processo baseado num conhecimento tácito (Garfinkel, 1967) sobre o corpo tem revelado as operações quotidianas efectuadas para classificar as nossas próprias acções de personificação e as acções dos outros. Nesta perspectiva, quer as observações participantes em estúdios de tatuagem, quer as entrevistas aprofundadas, são as actividades em que os membros produzem e gerem cenários de assuntos quotidianos organizados e [são] vistos como idênticos aos procedimentos dos membros para tornarem esses cenários "contáveis". O carácter "reflexivo" ou "encarnado" das práticas "reportáveis" e dos relatos constituem o cerne dessa recomendação. Quando falo em relatar, os meus interesses são direccionados para assuntos como os que referirei abaixo. Quero com isto dizer observável-e-reportável, isto é, acessíveis a membros como práticas situadas de looking-and-telling (Garfinkel, 1967: 1).

O senso comum sobre o processo de personificação tem enfatizado a relação entre a moda e as modificações do corpo como instrumentos que orientam o comportamento individual. Mesmo que algo esteja sempre implícito nas explicações, devido ao facto de um indivíduo tomar como dado adquirido a adesão de todos os participantes na prática, observar e recolher relatos sobre modificação corporal tem permitido uma compreensão mais profunda da racionalidade para além deste comportamento social e tem revelado a sua natureza fortemente enraizada no campo da reprodução. Foram encontradas quatro

\footnotetext{
${ }^{3}$ A primeira tem sido adotada para investigar práticas tomadas como adquiridas durante um mês de trabalho de campo num estúdio de tatuagem e de piercing em Estrasburgo (FR), 8 observações participantes de um dia em lojas selecionadas de tatuagem em Milão e no interior e por ocasião da Convenção Anual de Tatuagem de Milão em 2008. Este trabalho de campo tem implementado a compreensão do processo através do qual os indivíduos atribuem um significado às práticas de auto-modificação. O segundo focou 4 técnicas diferentes: a tatuagem, a escarificação, o piercing e a cirurgia estética. Os entrevistados (12 mulheres; 16 homens) foram selecionados entre três categorias de profissionais : cirurgiões, tatuadores, piercers e várias diferentes tipologias - relativas à idade e à atividade - de utilizadores comuns (Clientes/pacientes): estudantes, gerentes, jornalistas free-lance, empregadores, trabalhadores na indústria mecânica (ver Tab. 1), para fornecer uma amostra variada e eficaz.

${ }^{4}$ A reflexão feminista sobre o género efetivamente reconheceu a importância de tematizar este aspeto e tem assinalado uma relação entre as práticas de pesquisa e a possibilidade de desenvolver práticas sociais adequadas (Oakley 1981; Fox Keller 1989).
} 
respostas corporais específicas para a questão sobre a subjectividade: o corpo screen (ecrã), o corpo monumental, o corpo diferido, e o corpo consumível. Descreverei estas tipologias no ponto seguinte, explicando como cada um pode ser lido como o resultado de uma conceção particular das técnicas corporais utilizadas e como pode ser parte de uma performance da identidade.

\section{Corpos AUto-modelados. UMA TIPOLOGia}

Podemos detetar diferentes modelos corporais que parecem resultar das práticas de cuidado com a aparência e que podem ilustrar melhor o conceito de auto-apresentação no processo da modificação corporal.

Das entrevistas e das etnografias recolhidas, a variedade de tipologias corporais disponível no contexto social pode ser reduzida a quatro modelos principais: o corpo screen (ecrã), o corpo monumental, o corpo diferido, o corpo consumível. Cada um subscreve uma conceção das maneiras através das quais é suposto os homens e as muIheres utilizarem o idioma corporal, mas consiste numa simplificação da realidade complexa, reproduzida através das actividades situadas de auto-expressão. Não é suposto os tipos nesta série serem mutuamente exclusivos. Cada um representa características que aparecem em combinação com características de outro tipo na praxis. Além disso, devem ser vistas como figuras típicas, seguindo um enquadramento Weberiano (Weber, 1904), de acordo com o qual um processo de abstracção é operado, isolando e idealizando algumas características que pertencem aos casos empíricos.

O primeiro tipo corporal emerge da arena dos meios de comunicação internacionais e é similar a uma superfície neutra sobre a qual um indivíduo consegue operar interminavelmente e projectar imagens corporais aceites e promovidas pela cultura dominante. Para utilizar as palavras de uma tatuadora entrevistada, é:

"Um corpo o mais preservado possível, utilizando também a cirurgia estética. Talvez tatuado. Um corpo que não se permite desistir, É isso. Também em termos físicos. E a tatuagem pode ser aceitável. Porque, de qualquer maneira, normalmente é atribuída aos jovens. Se prestarem atenção ao que muitas mulheres dizem: 'Mas eu não posso fazê-lo. Já tenho 45 anos!' $\mathrm{Na}$ realidade, não vão morrer amanhã, pois não?"5

Pode de facto ser compreendido como um screen (ecrã), porque muitos atos de personificação seguem-se uns aos outros e são adaptados para produzir uma identidade adequada à situação. Se os pivôs, as estrelas do mundo pop, as estrelas de cinema se dedicam a uma quase radical remodelação do corpo, as pessoas comuns têm de seguir os seus ensinamentos e hábitos para transformarem em espectáculo o seu eu. Neste processo, a corporalidade torna-se o sempre insuficiente lugar para uma bricolage, uma peça temporária da nossa presença (Le Breton, 2008). Não obstante, este corpo não é "desenformado", ou caótico, para resumi-lo a um adjectivo mais adequado, poderia ser

5 (T5) refere-se à tatuagem, quinta entrevista. Neste caso particular a entrevistada é uma mulher de 45 anos, tatuadora profissional. 
definido como "instantâneo", uma materialização de uma lógica escondida: a exibição do eu. Identificações e personificação são então aceleradas para criar um fluxo contínuo, adaptado à aceleração das rotinas diárias.

Uma vez que o sistema da moda sugere a forma como a nossa aparência deveria ser inovada, o nosso corpo participa no processo de inovação, adquirindo os detalhes "corretos" graças à mais recente técnica corporal: um nariz pequeno conseguido através da cirurgia estética, um umbigo provocante graças ao piercing, uma anca sensual via a tatuagem. Cada parte deveria ser exibida para materializar um corpo jovem, sedutor e meta-cultural. Os projectos do corpo estão focalizados em atravessar o patamar do rejuvenescimento, para atingir o objectivo da erotização ou decoração para performances sexuais. O conhecimento implícito sobre o eu de apresentação é a capacidade de usar um tipo de corporalidade já pronta, que pode conter todas as características do momento, mesmo que de forma contraditória.

Ainda que seja ambivalente, este modelo corporal não pode ser muito detalhado: traços exóticos ou sub-culturais devem ser traduzidos em sugestões mais cativantes e para serem absorvidos na moda dominante. Os utilizadores são de facto uma comunidade ampla e indiferenciada, que tem absorvido o modelo globalizado belo, bem-sucedido e jovem, enquanto se tornou dependente da informação e das definições legitimando os grupos dominantes (Wilson et al. 1995), porque:

"Nós precisamos de informação, observamo-los e guardamo-los, mas nunca nos perguntamos porquê, ou se eles são verdadeiros ou falsos.// Nós precisamos de ficção". $\left(T_{3}\right)^{6}$

Este modelo opõe-se ao corpo monumental, resultado de um processo de domesticação, através do qual os indivíduos aprendem a prestar atenção às técnicas e aos procedimentos da personificação. Esta tipologia voluntarista é organizada e controlada pelos profissionais (cirurgiões, tatuadores, piercers), para produzir uma individualidade disciplinada.

Através da etnografia nos estúdios de tatuagem e observando as interacções na sala de espera dos hospitais e das clínicas, o corpo apareceu como um objectivo alcançável apenas se quatro características estiverem presentes no processo individual de modificação. É caracterizado por ser celular, determinando a distribuição espacial dos corpos; orgânico, assegurando que as actividades são "naturais" para os corpos; genético, controlando a evolução da actividade; combinatório, combinando a força de muitos corpos numa massa única. O resultado é uma corporalidade obtida após uma selecção de moldados e habitus, graças à informação transmitida de profissionais a pacientes/ clientes para fornecerem um know-how experiente e para estimularem a auto-supervisão e o comportamento auto-controlado.

As competências básicas sobre a nossa anatomia, psicologia, reacções à cirurgia e à medicina, ou tratamentos homeopáticos são funcionais para desenvolver um

${ }^{6}$ (T3) refere-se à tatuagem, terceira entrevista. Neste caso trata-se de um italiano de 30 anos, , utilizador e trabalhador na indústria mecânica. 
conhecimento sobre o corpo como ele é, enquanto a vontade para aceitar os regimes corporais é uma forma de criar uma comunidade que considera a modificação do corpo como um compromisso sério e trabalha para isso voluntariamente.

Neste enquadramento, a relação com a dor não é a principal característica, mas ainda é uma presença no trabalho para a personificação, basicamente influenciado por uma interpretação influenciada pelo género, de acordo com a qual as mulheres têm mais experiência com a dor e são mais atraídas para práticas dolorosas de domesticação corporal. Adicionalmente, representa uma semelhança significativa com práticas mais comuns de modificação do corpo como a competição desportiva, na qual um indivíduo tem de dominar o seu próprio corpo, os seus desejos e fraquezas, por forma a alcançar o mais alto nível de performance.

O conceito de performance é fundamental para a terceira tipologia corporal: o corpo diferido. Este modelo corporal ideal é parcialmente inspirado em instâncias sub-culturais, mas ao mesmo tempo está distanciado do limite extremo dos performers do corpo e das modificações radicais que operam no corpo, que são consideradas desvios arriscados - e por vezes inúteis - do idioma do corpo. O gosto estético é representado como um traço distintivo da cultura e do estilo de vida de cada um, assim tornando-se o objectivo dos profissionais que aspiram educar os seus clientes/pacientes no processo de personificação.

"O que eu tento fazer é encontrar uma forma melhor para os desejos do cliente, o que não significa alterar as ideias dele/dela, por vezes simplesmente chegam e não sabem que algo pode feito de uma maneira diferente, de uma maneira que é adaptada ao seu gosto estético pessoal." $\left(T_{4}\right)^{7}$

A materialização da identidade é assim baseada numa desconstrução de representações culturais, mas ao mesmo tempo é constituída por símbolos e significados disponíveis na vida quotidiana. Concorrendo a uma conceção prática de criatividade simbólica (Willis, 1990), os indivíduos estão empenhados numa colaboração para a re-interpretação de modelos corporais concebidos como sendo demasiado estereotipados e ao mesmo tempo úteis para uma actividade situada mais competente e mais compreensível. A semelhança com a moda aqui é evidente, mas é fortemente rejeitada nas narrativas dos entrevistados, uma vez que representa uma força homogeneizadora e enfraquecedora para o uso da nossa corporalidade.

O gosto pessoal é parcialmente interpretado numa perspectiva Bourdieusiana, sendo a expressão da educação de cada um e manifestando-se em hábitos e maneiras corporais (Bourdieu, 1979); por outro lado, ele difere parcialmente, incluindo uma conceção alargada de "estético" como atributo de expressões corporais sem conceitos, apoiado por estar fisicamente envolvido na experiência quotidiana (Maffesoli, 1990).

Uma última tipologia é o resultado da chamada cultura de consumo, por conseguinte, designá-la-ei por corpo consumível. Nesta perspectiva, o corpo individual torna-se um suporte para qualquer tipo de acessórios de moda, tendo como objectivo exibir-se na interacção. Podem ser encontradas semelhanças entre este tipo e o corpo ecrã (screen),

${ }_{7}$ (T4) quarta entrevista, tatuagem, mulher de 30 anos, tatuadora profissional. 
se o lermos como um "corpo em exposição", mas sendo diferente do primeiro modelo na medida em que a sua redução a uma mercadoria através das técnicas corporais é ainda mais importante do que a sua contínua metamorfose.

Através da mercantilização, efectivamente qualquer característica pode ser comprada e vendida e a identidade ou a identidade de género pode tornar-se parte deste processo, tal como vestidos ou implantes cirúrgicos, e pode atravessar as fonteiras das identidades nacionais. No mundo contemporâneo, de facto, o mercado material movimenta um fluxo de produtos de qualquer parte do mundo para qualquer canto do planeta e o supermercado cultural global faz circular um fluxo de informação e de identidades potenciais de um qualquer local para outro. Estas duas formas do mercado contribuem para construir um contexto no qual os indivíduos podem localizar as suas narrativas e dar uma estrutura à sua modulação de identidade (Mathews, 2000).

Teoricamente, qualquer um pode ter acesso às técnicas para a manutenção do corpo se o desejar fazer. Além do mais, o desejo do indivíduo em ser suficientemente meritório para investir dinheiro na sua própria melhoria e na aparência física, como é sugerido pelos meios de comunicação internacionais, para se adequar ao contexto, pode ser traduzido na necessidade de apoiar qualquer tipo de produto. Os princípios desta teoria podem encontrar-se num catálogo promovendo uma famosa clínica italiana de cirurgia estética

Porque não entrar num vestiário e tentar qualquer tipo de fatos de banho sem ter de dizer "este não, porque me faz gorda, nem este porque não me favorece, nem aquele porque não me esconde a barriga". Em vez disso, pense em como seria bom se pudesse dizer a si próprio/a "Posso comprá-los todos porque o meu corpo adequa-se a qualquer modelo!" Aquele saco de compras no seu braço que contém um micro-biquini seria uma verdadeira conquista para que goste cada vez mais de si. ${ }^{8}$

Estes princípios de personificação podem ser aplicados quer às mulheres, quer aos homens, que aprenderam como um corpo bonito e bem cuidado é parte integrante de um ritual de socialização colectivo. A sociedade não impõe qualquer uniforme, o corpo consumível torna-se o único uniforme que todos podem usar enquanto cuidam das suas aparências. Não é requerida qualquer característica típica para esta actividade, apenas a solicitude em substituir as características pessoais de cada um por características mais funcionais. Tal como qualquer tipo de produto, o corpo consumível subscreve a nossa identidade e as competências de género.

\section{RUMO A UMA PERSONIFICAÇÃo MAIS REFLEXIVA?}

As fontes que fornecem informação sobre o que deveria ser entendido como socialmente útil são muitas hoje em dia, que vão desde a família aos meios de comunicação internacionais, do grupo de pares à cultura de consumo, da arte corporal à moda, da ciência à saúde. O que é comum a estas diferentes fontes é a participação num processo

\footnotetext{
${ }^{8}$ Cfr. www.laclinique.it, 29/08/2010.
} 
de produção de uma estética do corpo, que deriva de um sistema típico de cinema: é extremo na medida em que quer parecer provocante, preciso e calculado e torna o corpo o mais bonito objecto de consumo (Vigarello, 2003). Estes esquemas de conduta, implicados nas práticas de modificação corporal estão longe de serem neutros e inofensivos, uma vez que participam na tarefa diária desempenhada por homens e mulheres: preservar a ordem social específica (Goffman, 1979). A força e durabilidade desta ordem não resulta do facto de ser verdade ou evidente, mas por nunca ser questionada, nunca ser discutida e ser sempre tomada como um dado adquirido, como parte da realidade da situação (Garfinkel, 1967).

Uma vez que é o resultado de uma série de procedimentos de questionamento, de procura de respostas, de indagações - e não apenas da manipulação de informação - o esquema através do qual interpretamos e materializamos o nosso eu depende das técnicas fornecidas pela sociedade aos seus membros. Nas últimas décadas, o trabalho realizado nas interacções face a face tem envolvido o trabalho corporal de forma crescente (Turner, 1984) e a gama de técnicas corporais tem sido alargada, bem como o grupo de pessoas que recorre à tatuagem, à cirurgia estética e ao piercing, para incrementar a sua própria performance social. A moda deu um forte impulso a este processo e definiu as formas através das quais o nosso corpo deve ser concebido: um objecto que exprime a nossa identidade e que deveria ser regularmente (ou melhor, o mais depressa possível) inovada.

Após os modelos ilustrados anteriormente, um último modelo emergiu nos relatos das pessoas entrevistadas. Aparece como uma abstracção, em contraste com as quatro tipologias mencionadas e com os ditames da moda. Parece transversal a todas elas e será designado por o corpo convivial, uma identidade alcançada através de uma comunicação menos funcional e mais reflexiva do nosso eu na vida quotidiana.

"Não se trata fazer uma ou outra coisa. É uma questão de analisar algo que esteja a acontecer, de aprender como o corpo se cura e reage e como muda. É uma disciplina que pode fazer acontecer na sua vida e que pode mudar a sua forma de ser". $\left(\mathrm{S}_{2}\right)^{9}$

É um feito permitido pelo abrandamento e pela redução do impacto das representações, mais do que pela seleção entre as inúmeras sugestões transmitidas pelos meios de comunicação, nem seguindo a lógica da disciplina, nem cultivando a peculiaridade do gosto.

"Tento persuadir as pessoas de que não deveriam andar numa correria, não se deveriam forçar a fazer coisas, há limites naturais que deveriam ser respeitados, o tempo, deve ser paciente, estar atento, observar o que acontece ao corpo, compreender e reflectir sobre tudo." $\left(\mathrm{P}_{3}\right) 10$

\footnotetext{
${ }^{9}$ (S2) refere-se à escarificação, segunda entrevista. Neste caso, trata-se de um homem de 35 anos, piercer francês, especializado na prática da escarificação

${ }^{10}\left(\mathrm{P}_{3}\right)$ refere-se ao piercing, terceira entrevista. Aqui trata-se de um italiano de 36 anos, piercer especializado em diferentes técnicas de modificação corporal.
} 
Na opinião dos entrevistados, este último modelo implica uma relação mais consciente com o corpo e encontra muitos obstáculos que variam entre a educação, que reduziu a responsabilidade pessoal a uma fantochada, até à descoberta da dor, que se tornou um problema físico evitável; desde a cultura de consumo, cuja importância excessiva reduz os desejos e impõe as imagens estereotipadas relacionadas com elas, com o nosso cuidado pessoal, cujo condicionamento mecânico pode terminar numa mera domesticação do gosto estético das massas. Para ter sucesso nesta tarefa, a influência das imagens deveria ser redefinida e enfraquecida através de uma reflexão sobre os nossos desejos. Esta tipologia produz mais questões do que respostas, uma vez que aparece como um modelo de personificação reflexiva, procurando um significado num cenário crescentemente saturado com modelos objetificados, finamente gravados e capazes de se imporem através da ilusão da auto-expressão competente.

Apesar da identidade ser compreendida como o resultado de um trabalho destinado a mover-se dialecticamente entre a auto narração e o uso de um código comum de personificação, criando uma auto narração compreensível, parece ser o problema mais urgente influenciando as práticas de modificação e orientando-as para materializações de tipologias corporais estetizadas, mais do que subversivas. A tradição da moda em Itália tem ajudado a produzir um modelo de auto-representação que é fortemente dependente de definições dominantes de aparência corporal e ainda relutante a grandes inovações, até ao ponto em que a moda pode, de certa forma, parecer conservadora (Mora, 2009). Esta tradição parece ter influenciado as práticas corporais e fomentado modelos corporais que estão em sintonia com as representações nas imagens de moda. Um esforço em manter uma certa distância destes tipos aparece hoje apenas como um comportamento exclusivo. É um trabalho lento sobre a reflexividade, desempenhado por profissionais nos seus estúdios e consultórios, mas pode conduzir a performances de identidade como realizações de práticas de personificação mais críticas e responsáveis. Esta perspectiva diferente parece abandonar a interpretação da moda como uma mera proliferação de estilos (Polhemus, 1998; 2004), a favor de uma maneira diferente de entrar no seu espaço simbólico, focado num projecto corporal duradouro e numa capacidade incrementada de pedir melhores resultados. Supervisionar as formas através das quais este processo está a ser desenvolvido pode ser um recurso útil também para o próprio sistema da moda que está a passar por um processo de transformação, quer nas suas dimensões materiais, quer simbólicas.

Traduzido por João Paulo Abreu Silva.

\section{REFERÊNCIAS}

Adams, J. (2009) "Bodies of Change: A Comparative Analysis of Media Representations of Body Modification Practices", Sociological Perspectives, Vol. 52, No. 1: 103-129.

Baudrillard, J. (1979) De la Séduction, Paris : Galilée. 
Barthes, R. (1982) “Encore le Corps Critique”, nn. 423-424.

Bordo, S. (1993) Unbearable Weight. Feminism, Western Culture and the Body, Berkeley: University of California Press.

Bourdieu P. (1979) La Distinction. Critique Social duJjugement, Paris: Minuit.

Butler, J. (1990) Gender Troubles. Feminism and the Subversion of Identity, Routledge: New York.

Butler, J. (2003) Bodies that Matter. On the Discursive Limits of Sex, New York: Routledge.

Codeluppi, V. (1995) "Il Corpo Flusso. La Moda al di là del Narcisismo", in Ceriani G. and Grandi R. (eds.), Moda: Regole e Rappresentazioni. Il Cambiamento, il Sistema, la Comunicazione, Milan: FrancoAngeli, Milan, pp. 82-90.

Corbin, A., Courtine, J.-J, de Baecque A. e Vigarello, G. (2008) (eds.) Histoire du Corps. III - Les Mutations du Regard. Le XXe siècle, Paris: Seuil.

Crane, D. (2000) Fashion and its Social Agendas: Class, Gender, and Identity in Clothing, Chicago/London: Chicago Press.

Davis, K. (2002) “'A Dubious Equality': Men, Women and Cosmetic Surgery”, Body and Society, 8, 1: 49-65.

Davis, K. (1995) Reshaping the Female Body: The Dilemma of Cosmetic Surgery, London: Routledge.

Entwistle. J. (2000) "The Fashioned Body" in Entwistle J. and Wilson E. (2001) Body Dressing, Oxford: Berg, pp. 33-58.

Diaz, Soloaga P.; Muñiz, Muriel C. (2008) "Women Stereotypes Portrayed in Print Ads by Luxury Fashion Brands. A Content Analysis from 2002 to 2005", Observatorio (OBS*) Journal, 4: 291-305.

Douglas, M.; Isherwood, B. (1979) The World of Goods: Towards an Anthropology of Consumption, New York: Basic Books.

Evans, C.; Thornton, M. (1991) "Fashion, Representation, Femininity", Feminist Review, No. 38: 48-66.

Featherstone, M. (2000) (ed.) Body Modification, London: Sage.

Featherstone, M.; Hepworth. M.; Turner, B. (1991) The Body: Social Process and Cultural Theory, Thousand Oaks/London/New Delhi: Sage.

Fox, Keller E. (1989) “Holding the Centre of Feminist Theory", Women Studies' International Forum, 12, 3: 313-318.

Garfinkel, H., (1967) Studies in Ethnomethodology, Englewood Cliffs, Prentice Hall.

Goffman, E. (1963) Behavior in Public Places: Notes on the Social Rrganization of Gatherings, New York: Free Press.

Goffman, E. (1979) Gender Advertisement, Cambridge: Harvard University Press.

Howson, A. (2005) Embodying Gender, London/Thousand Oaks/New Delhi: Sage.

Irigaray, L. (1977) Ce Sexe qui n'Est pas Un, Paris: Minuit.

Le Breton, D. (2002) Signes d'Identité. Tatouage, Piercing et autres Marques Corporelles, Paris : Métailié. 
Le Breton, D. (2008) Anthropologie du Corps et Modernité, Paris : PUF.

Leveratto, J.M. (2006) “Lire Mauss. L'Authentification des Techniques du Corps et ses Enjeux Épistémologiques”, Le Portique, 17: 6-17.

Maffesoli M. (1990) Au Creux des Apparences, Paris: Plon.

Materassi L., (2010) "Life Style Magazines: Immaginari al Maschile" in Mora E. (ed.) Geografie della Moda, Milan: Franco Angeli, pp. 50-61.

Mathews, G. (2000) Global Culture/Individual Identity: Searching for Home in the Cultural Supermarket, London/New York: Routledge.

Mauss, M. (1950) “Les Techniques du Corps”, Sociologie et anthropologie, Paris: PUF, pp. 365-386.

Merleau-Ponty, M. (1945) Phénomenologie de la Perception, Paris: Gallimard.

Mora, E.(2009) Fare Moda. Esperienze di Produzione e Consumo, Milan: Bruno Mondadori.

Oakley, A. (1976) Sex, Gender and Society, London: Gower.

Ory P. (2008) "Le Corps Ordinaire" in Corbin A.,Courtine J.-J, de Baecque A. e Vigarello G. (eds.), Histoire du Corps. III - Les Mutations du Regard. Le XX' siècle, Paris: Seuil, pp. 129-161.

Pietropolli, Charmet G.; Marcazzan, A. (2000) Piercing e Tatuaggio. Manipolazioni del Corpo in Adolescenza, Milan: FrancoAngeli.

Polhemus, T. (1998) "In the supermarket of style" in Redhead S. (a cura di) The Clubcultures Reader: Readings in Popular Cultural studies, Oxford: Blackwell.

Polhemus, T. (2004) Hot Bodies, Cool Styles. New Techniques in Self-Adornement, London: Thames \& Hudson.

Robin, A. (2005) Pour une Sociologie du “Beau Sexe Fort”, Paris : L'Harmattan.

Ruggerone, L. (2006) “The Simulated (Fictitious) Body: The Production of Women's Images in Fashion Advertisement”, Poetics, 6, 34: 354369.

Shilling, C. (2003) The Body and Social Theory, London: Sage.

Simmel, G. (1904) “Fashion”, International Quarterly, 1904, X, 1: 130-155.

Simmons, R. G.; Blyth, D. A.; McKinney, K. L. (1983) "The Social and Psychological Effects of Puberty on White Females" in Brooks-Gunn J. and Petersen, AC Girls at Puberty: Biological and Psychological Perspectives, New York: Plenum.

Stagi L. (2008) Anticorpi. Dieta, Fitness e Altre Prigioni, Milan: FrancoAngeli.

Steele V. (1985) Fashion and Eroticism: Ideals of Feminine Beauty from the Victorian Era to the Jazz Age, Oxford: Oxford University Press.

Stella, R. (1998) Prendere Corpo: L'Evoluzione del Paradigma Corporeo in Sociologia, Milan: FrancoAngeli.

Travaillot, Y. (1998) La Sociologie des Pratiques d'Entretiens du Corps, Paris: PUF.

Turner, B.S. (1985) The Body and Society, Oxford: Basil Blackwell.

Vigarello, G. (2003) Histoire de la Beauté. Le Corps et l'Art d'Embellir de la Renaissance à nos Jour, Paris: Seuil. 
Weber, M. (1904) «Die Objektivität Sozialwissenschaftlicher und Sozialpolitischer Erkenntnis» Archiv für Sozialwissenschaft und Sozialpolitik XIX : 22-87.

Willis, P. (1990) "Symbolic Creativity" in Willis, P. Common Culture. Symbolic Work at Play in the Everyday Cultures of the Young, Milton Keynes: Open University Press.

Wilson, C.C.; Gutierrez F.; Chao, L.M. (2003) Racism, Sexism and the Media: The Rise of Class Communication in Multicultural America, Thousand Oaks/London/New Delhi: Sage.

Wilson, E. (195) Adorned in Dreams: Fashion and Modernity, London: Tauris.

Wolf, N. (1991) The Beauty Myth. How Images of Beauty are used Against Women, New York: Bantham Doubleday.

Wykes, M.; Gunter, B. (2005) The Media and Body Image, London/Thousand Oaks/New Delhi: Sage. 